LEITURA - ESPAÇOS HÍBRIDOS: n. 28, n.29, p.43-58.

\title{
O ENSINO DA CONVERSAÇÃO EM LÍNGUAS ESTRANGEIRAS
}

\section{Maria Inez Matoso Silveira}

Resumo: Neste artigo, a conversação é considerada como um fator importante para a aquisição da língua estrangeira. Mas para que seja razoavelmente eficaz, o ensino da conversação deve ser planejado a partir do seu caráter pragmático e da dinâmica de sua organização. A autora comenta sobre a forma distorcida como a conversação é tratada na abordagem e métodos estruturais e defende a abordagem comunicativa como a mais propícia para o ensino da conversação, considerando a junção da tendência centrada nas tarefas comunicativas e a tendência centrada nos atos de fala (ou funções comunicativas) como a opção metodológica mais eficaz para o processo de ensino e aquisição dessa habilidade.

Palavras-chave: Prática conversacional; natureza da conversação; abordagens de ensino; tarefas comunicativas; funções comunicativas

Neste artigo, trataremos da prática da conversação no ensino de línguas estrangeiras (LEs) e sua suposta contribuição para a aquisição e aprendizagem da língua. Acreditamos que o assunto merece uma discussão minimamente esclarecedora ${ }^{1}$ na medida em que se reveste de uma certa complexidade que se relaciona diretamente com as concepções de língua e de aprendizagem de LEs que permeiam não só a prática pedagógica e metodológica dos profissionais desse ramo, como também as propostas curriculares que estão na base desse ensino nos centros especializados e nas escolas regulares.

(*) Professora do Cedu/Ufal, Doutora em Lingüística - UFPE.

1 A bem da verdade, na chamada cultura de aprender e de ensinar línguas, há pessoas que confundem certos conceitos como oralidade, expressão oral, fala (de forma inespecífica e vaga) e prática oral (para diversos fins) com conversação. Há quem ache que saber dizer frases soltas numa LE ("The book is on the table") é saber falar aquela língua, mesmo sem levar em conta o aspecto interacional. 
O problema do ensino-aprendizagem da conversação em LEs, além da necessária vinculação à diversidade das abordagens e métodos de ensino acima mencionada, ainda enfrenta certas "crenças" e preconceitos que, mesmo aparecendo, às vezes, de forma velada, mas sempre sem fundamentação consistente, perturbam e confundem a efetivação do ensino das habilidades básicas nesse tipo de educação lingüística. Nesse sentido, veja-se a difundida crença de que se pode ensinar e aprender bem a gramática de uma LE, "mas a conversação não pode ser 'ensinada'; ela só pode ser 'aprendida' quando o indivíduo entra em completa imersão; vale dizer, quando as pessoas passam a viver ou a estudar num país onde a LE é falada ou, no mínimo, quando convivem com estrangeiros falantes nativos da língua-alvo". Ao lado dessa, e também decorrente dela, consolidou-se outra crença infundada de que "só se pode aprender a conversar numa LE tendo-se aulas com professores nativos". Essas idéias talvez possam ser atribuídas, em parte, às imprecisões acarretadas pelo chamado método direto, que se contrapuseram às práticas tradicionais de ensino de LEs nos finais do século XIX. Convém lembrar que essa tendência - o método direto - valorizava, nas suas origens, a figura do preceptor (geralmente um estrangeiro) como professor ideal (SILVEIRA, 1999, p.38-41).

Naturalmente, essas visões têm ajudado a legitimar a manutenção, nas nossas escolas, da abordagem e dos métodos tradicionais, centrados na língua escrita ${ }^{2}$, que terminam se deteriorando no ensino de conteúdos em que predominam os tópicos gramaticais isolados e listas de vocabulário descontextualizado, e que se repetem ao longo dos anos de aprendizado escolar. É evidente também que a abordagem tradicional acaba "naturalizando" a existência, no nosso ensino básico, de um grande contingente de professores que não têm um domínio mínimo da conversação nas LEs que ensinam.

A abordagem estrutural, a bem da verdade, procurou dar primazia à língua oral, mas seus pressupostos e suas atividades de ensino terminaram dificultando ou, no mínimo, postergando a emergência da conversação "espontânea" entre os aprendizes.

2 Sabe-se que a concepção tradicional de língua, principalmente quando se manifesta no chamado método de gramática e tradução, não valoriıa a fala como objeto digno de estudo, por considerar que a língua falada é algo desordenado, espúrio e não-passível de sistematização (SILVEIRA, 1999, p.45). 
Também, praticamente, em nada ou muito pouco contribuiu para melhorar a performance do professor como falante da LE que ensina. Além disso, os métodos estruturais (audio-oral, audiovisual, etc.) exigiam um certo aparato técnico-metodológico que os professores de escolas regulares geralmente não tinham. Assim, os métodos estruturais sempre encontraram mais guarida nos centros especializados de ensino de línguas. Nas escolas regulares, a sua adoção se deu mais por força de sua presença considerável nos livros didáticos, principalmente durante e depois da década de 70. Entretanto, os métodos estruturais logo se deterioraram em práticas de repetição enfadonha e sem sentido, assim mesmo mais voltadas para os exercícios escritos, e, em boa parte, enfatizando tópicos gramaticais explícitos.

Quanto à abordagem comunicativa, consideramos que sua contribuição para a aquisição e prática da conversação em LEs se dá de forma mais significativa para o aprendiz, além de poder trazer bons dividendos para o desenvolvimento das outras habilidades produtivas e receptivas. Evidentemente, há, também, como em todas as metodologias, algumas restrições e limites a serem considerados, como ressalta Almeida Filho $(1983,1986)$. Entretanto, convém considerar que tal abordagem ainda se encontra praticamente desconhecida da maioria dos professores nas nossas escolas regulares, pelo menos na nossa comunidade (Maceió) e mesmo no nosso estado e região. Pode-se comprovar uma pequena amostragem desse fato através dos relatórios de observações de aulas de alunos da disciplina Estágio Supervisionado de Ensino de Inglês, na Ufal, em turmas sob a nossa orientação. A despeito disso, uma proposta de ensino de cunho comunicativo e nocional-funcional assumida pela Secretaria Municipal de Educação de Maceió, através das ações de Formação Continuada, sob a nossa responsabilidade, tem tentado renovar o ensino de inglês nas escolas municipais de nossa cidade $^{3}$, embora se saiba que nem todos os professores tenham condições de implementá-la a contento.

Neste trabalho, pretendemos defender, primeiramente, que a prática da conversação no ensino-aprendizagem de línguas é algo extremamente útil e desejável, até porque a conversação se configura

Trata-se da Proposta de Ensino da Língua Inglesa na Escola Fundamental - $5^{a}$ à $\delta^{a}$ Série. Semed-Maceió, que vem sendo implementada desde 1998. 
como a "matriz para a aquisição da linguagem" (LEVINSON, 1983. p.284) ${ }^{4}$. A viabilidade e a eficácia das propostas para o ensino dessia habilidade nas LEs é o que discutiremos mais adiante. Antes disso. parece-nos de primordial importância perguntar-se o que é conversação, o que é conversar; enfim, como se dá, e quais são as características e os componentes desse importante evento comunicativo que pode se realizar através de inúmeros gêneros discursivos da língua oral. Depois disso, parece-nos interessante verificar as formas como a conversação foi concebida nas principais abordagens e métodos de ensino de LEs, enfatizando, finalmente, duas tendências de ensino da conversação dentro da abordagem comunicativa.

\section{A natureza da conversação}

Sem dúvida, a conversação é uma atividade extremamente complexa e, certamente, boa parte da dificuldade na decisão dos professores sobre o que fazer numa aula de conversação é devida à sua própria natureza. Diante disso, faz um pouco de sentido aquela pergunta intrigante, desta vez posta por Richards (1990, p.67): "Pode a conversação ser ensinada ou ela é adquirida simplesmente ao se praticá-la?". E é com base neste e noutros autores que tentaremos sucintamente examinar a natureza da conversação e alguns dos seus mais relevantes aspectos.

Comecemos, pois, esta breve análise, salientando a natureza multifacetada da conversação. Tendo sido, por muito tempo, considerada como algo caótico e avesso a qualquer estudo ou sistematização, a conversação passou a constituir-se como objeto de estudo com o advento da Análise da Conversação a partir da década de 60, na linha da Etnometodologia e da Antropologia Cognitiva (MARCUSCHI, 1986, p.6). Segundo esse autor, a Análise da Conversação "é uma tentativa de responder a questões do tipo: como é que as pessoas se entendem ao conversar? Como sabem que estão se entendendo? Como sabem que estão agindo coordenada e cooperativamente?" Obviamente, não pretendemos discorrer aqui sobre todos os complexos fatores e elementos envolvidos pela $\mathrm{AC}$; $\mathrm{O}$ apelo que a ela aqui se faz restringe-se apenas ao reconhecimento de

Marcuschi (1986, p.14), além de fazer tal citação, lembra que a conversação é um gênero básico da comunicação humana e que cla realiza, da forma mais contundente, o princípio dialógico da linguagem. 
que alguns subsídios provenientes dessa área de estudos são imprescindíveis para se elaborar ou conduzir qualquer programa de ensino que pretenda focalizar a conversação como fator relevante para a aquisição e a aprendizagem de LEs.

Grosso modo, é conveniente considerarmos, antes de tudo, que a conversação é uma interação social lingüístico-discursiva que ocorre entre, no mínimo, dois interactantes; é necessariamente situada num contexto (cenário) e gira sempre em torno de um tópico (assunto). Os interactantes ou interlocutores geralmente assumem papéis sociais nessa interação, cabendo a eles interpretar as intençōes que são veiculadas através das falas do diálogo (SOUZA, 1983). Evidentemente, a conversação é um processo colaborativo e reflete as regras e procedimentos que regem as interações face a face, além das restrições que permeiam os usos sociais da língua falada.

Nessa perspectiva, considera-se também que o usuário de uma determinada língua, para ter um desempenho eficiente nas suas interações lingüísticas, há de possuir certas competências, dentre as quais se destacam:

- a competência gramatical (estrutura morfossintática da língua);

- a competência lexical (vocabulário);

- a competência comunicativa ou retórica (uso adequado da língua, ou seja, de atos de fala, conforme as situações);

- a competência textual (discursiva), que se traduz na preservação da coerência temática e da coesão (entre as proposições).

Como salientam os teóricos da Análise da Conversação e também como lembra Richards (1990, p.70), uma das características estruturais da conversação é que sua progressão se dá através de turnos. Assim, de forma alternada, o falante pode tornar-se ouvinte e vice-versa. A condução e o controle do sistema de progressão alternada dos turnos na conversação envolvem o uso de várias estratégias. Sendo assim, existem estratégias para tomar o turno, para mantê-lo e também para finalizá-lo. Dentre outros componentes da conversação são dignos de atenção os marcadores conversacionais e os recursos para correções e reparações. A questão da coerência também se coloca como aspecto importante. A propósito, Paiva (2001, 
p.90) assinala que "quando dois ou mais indivíduos participam de uma conversação, eles estão coordenando conteúdos e ações, ou seja, os interlocutores fazem um esforço mútuo para construir sentido, isto é, para construir um texto coerente".

Com efeito, muito mais pode ser dito sobre a conversação nessa visão discursiva e etnográfica. Mas, acreditamos que o exposto já é suficiente para os fins a que nos propomos por enquanto, que é o cotejo entre a evolução das abordagens, métodos e técnicas de ensino de LEs mais difundidos e a visão de conversação que nelas estão subjacentes. Estamos nos referindo principalmente aos métodos de base estrutural e situacional.

\section{O ensino da conversação nos métodos de base estrutural}

A abordagem estrutural de ensino de LEs, como se sabe, é caudatária da psicologia behaviorista, e, como tal, a aquisição dal língua é vista como uma formação de hábitos através de condicionamentos. Do ponto de vista do ensino de LEs na concepção estrutural, a técnica mais eficiente para o ensino da língua é o uso de drills, que são exercícios sistemáticos visando à memorização de padrões estruturais. Mesmo dando-se primazia à língua oral, isso não significa, entretanto, que os treinos orais desenvolvidos nos métodos estruturais (audiolingual e audiovisual, etc.) possam ser considerados como práticas conversacionais no sentido pragmático do termo. Confundem-se várias atividades que envolvem o treino oral para vários fins (memorização de um tópico gramatical, treino fonético, entonação, etc.) com conversação. Ademais, repetir, memorizar e mesmo "dramatizar" um diálogo na base do "parroting" não é interagir. Na realidade, o que se observa é que as falas dos diálogos são escolhidas de acordo com os padrões estruturais que se quer treinar. Acredita-se, nessa abordagem, que o aprendiz deve ser primeiramente treinado para usar padrões estruturais de forma cuidadosa e graduada e só assim ele poderá vir, posteriormente, a falar "espontaneamente" um dia. O grande problema é que esse dia da emergência da fala espontânea e proficiente é sempre postergado e para muita gente geralmente nunca chega.

Acreditamos não ser necessário discutirmos aqui as inúmeras técnicas e toda a parafernália de recursos auxiliares do ensino que se engendraram para o ensino da expressão oral na abordagem estrutural. Mais interessante é constatar que o investimento no ensino da 
"conversação" nos métodos estruturais sempre termina em frustração, mesmo depois de submeter o aprendiz a um interminável e aborrecido treinamento de repetição, reelaboração e memorização. Ainda na década de 70, já eram evidentes algumas críticas, além da conhecida posição explícita de Chomsky, contrárias à concepção behaviorista da linguagem e defendendo o aspecto mentalístico e criativo na aquisição da língua. Alegava ele que os falantes não estão condenados a falar meras variações das sentenças que ouvem ou a responder automaticamente a estímulos que os rodeiam.

Vale dizer que, mesmo entre os que defendiam e divulgavam os pressupostos dos métodos estruturais, a exemplo de Cosgrave (1975), já se reconhecia a necessidade de um componente "mais comunicativo" no ensino de inglês; e, da mesma forma, um artigo de Garner \& Schultz, também de 1975, já denunciava um "missing link" no ensino de inglês. Esse "elemento faltante", segundo os autores, se refere à necessidade de um método que fizesse uma ligação entre as estruturas exercitadas através dos drills e as situações reais de comunicação fora da sala de aula.

Já o método situacional e o estruturo-global-audiovisual (SGAV), muito difundidos entre nós no ensino do inglês e também do francês até meados da década de 80 , mesmo mantendo a mesma base estrutural, inovaram um pouco, já que consideram a importante questão do contexto, dos usos da língua em várias situações da vida na cultura ocidental, como, por exemplo, no aeroporto, no restaurante, no supermercado, no consultório médico, etc. Como a preocupação ainda era centrada na forma gramatical, o apelo aos drills ainda era bem considerável. Mas já se dava muito valor aos sketches, às dramatizações e às simulações (mesmo muito controladas) em que se esperava promover uma aprendizagem mais significativa para a prática das estruturas lingüísticas (SILVEIRA, 1999, p.66). A crítica que se faz a esse método é que as estruturas treinadas eram aprendidas de forma estanque, como se só servissem para aquelas situações. Outra queixa que se tinha é que, na vida real, as situações nem sempre aconteciam conforme o "script" treinado em sala de aula. Daí a natural frustração do aprendiz ao perceber a diferença entre as situações idealizadas e a situações reais, levando-o a dar como "inútil" muito do que aprendeu na escola ou na "cultura". 


\section{A conversação e seu ensino na abordagem comunicativa}

A abordagem comunicativa distingue-se das abordagens lingüístico-gramaticais-formais por deslocar o foco do código da língua por si mesmo para o uso da língua e seus entornos. Podem ser citados dois elementos fundamentais que impulsionaram o turning point para essa abordagem: a teoria dos atos de fala e a noção de competência comunicativa ${ }^{5}$. Sem dúvida, ao valorizar os componentes pragmáticos da interação lingüística, a abordagem comunicativa se presta de forma mais eficiente ao ensino da conversação. Além disso, vale ressaltar que, segundo alguns pesquisadores em aquisição de segunda língua, a exemplo de Hatch (1978), a própria competência lingüística emerge gradualmente com a prática da conversação.

Um dos procedimentos relevantes para o planejamento e a elaboração de um programa de ensino da conversação é a chamada needs analysis, ou seja, a análise das necessidades comunicativas dos aprendizes. Essa análise deve, portanto, fornecer informações sobre os tópicos conversacionais e as funções comunicativas (ou atos de fala, se se quer) que os aprendizes precisam dominar para um bom desempenho nas suas tarefas interacionais. Recomenda-se também que as atividades para o desenvolvimento das habilidades da produção oral e da compreensão auditiva sejam feitas de forma separada, já que elas envolvem atividades psicomotoras diferentes. Assim, o aprendiz pode progredir em cada uma delas na proporção requerida para $\mathrm{um}$ desempenho razoável em cada habilidade (RILEY, 1985, p.354).

Um outro aspecto a ser considerado num curso de conversação é a questão dos registros, ou seja, as variações lingüísticas que ocorrem de acordo com as situações sociais. Com efeito, os aprendizes não só precisam interagir entre eles num registro

5 Segundo a teoria dos atos de fala (AUSTIN, 1962/1990; SEARLE, 1969/1981), a linguagem humana é uma forma de atividade social. Desse modo, quando dizemos algo, estamos realizando um ato (afirmando. prometendo, elogiando, reclamando, convidando, etc.). Nesse paradigma, a visão, o foco da descrição da língua passou do que ela é, para o que cla faz. Já a competência comunicativa (HYMES, 1971) é um conceito ligado à etnografia da comunicação. Grosso modo, a competência comunicativa pode ser entendida como a habilidade de uso adequado da língua nos diversos contextos e situações sociais. 
informal, mas também precisarão de um registro mais elaborado para interagirem em contextos e situações que exigem formalidade.

Conforme Richards (1990, p.76), dentro do movimento comunicativo de ensino de LEs, existem duas grandes tendências de se elaborar programas de conversação: uma tendência ou abordagem indireta, em que a competência conversacional é considerada como um produto do envolvimento dos aprendizes em atividades interacionais; e uma segunda tendência, em que o trabalho é mais direto, mais voltado às micro-habilidades específicas, estratégias e processos que ocorrem na conversação fluente.

\section{O ensino da conversação através de tarefas comunicativas - uma abordagem indireta}

O ensino da conversação na abordagem indireta tem como técnica básica a utilização de tarefas comunicativas ${ }^{6}$, através das quais os aprendizes interagem entre si utilizando a língua-alvo em atividades conversacionais de forma significativa. Acredita-se que, através dessas atividades, os aprendizes vão gradualmente adquirindo a língua, desenvolvendo não só a competência lingüística como também a desejada competência comunicativa. De acordo com Nobuyoshi e Ellis (1993, p.204, apud Almeida Filho, 2000, p.30), as tarefas comunicativas devem:

a) ter um propósito comunicativo (não apenas um objetivo lingüístico);

b) ter o foco na mensagem e não no código lingüístico;

c) ter algum tipo de "lacuna" (uma lacuna de informação ou de opinião);

d) ser uma oportunidade para a negociação ao desempenhar a tarefa;

e) permitir aos participantes a escolha de fontes (verbais ou não).

Vale salientar, nessa abordagem indireta, o papel do professor, não só como um negociador na proposição das tarefas e atividades para os alunos mas também como um estimulador da negociação de sentidos entre os próprios alunos. De acordo com Richards (1990),

Tarefas comunicativas são técnicas de ensino que geralmente envolvem os alunos na compreensão, produção e interação na LE. Para um entendimento mais detalhado sobre as tarefas comunicativas no ensino de LEs, ver Nunan (1989) e Almeida Filho (2000). 
essas tarefas comunicativas não têm a pretensão de ensincır a conversação, mas de promover oportunidades para os alunos se engajar numa interação conversacional. Em termos práticos, isso significa que o professor deve organizar os alunos para o trabalho em pares e/ou em grupos e lhes pedir que cumpram determinadas tarefas que exigem interações lingüísticas. $O$ trabalho deve ser orientado de modo que os aprendizes se sintam motivados e engajados, a fim de que essas atividades se realizem como verdadeiras tarefas comunicativas (cujo foco deve recair mais no significado) e não se transformem em meros exercícios lingüísticos (cujo objetivo recai na forma lingüístico-gramatical).

Evidentemente, há limitações para um ensino de conversação baseado apenas em tarefas comunicativas, como apontam Richards (1990, p.78) e Almeida Filho (2000, p.41). Com efeito, há de se refletir sobre questões negativas como a possibilidade de um conhecimento fragmentado da língua; da recorrência e cristalização de imprecisões gramaticais e mesmo comunicativas; da aquisição e manutenção de uma "interlíngua baixa" proveniente da imersão prematura do aluno numa atividade conversacional "livre" sem um conhecimento estruturado da língua e outros efeitos que poderão advir de tal prática. Entretanto, concordamos com Almeida Filho (ibidem) ao ponderar que há um procedimento razoavelmente eficaz para a remediação desses efeitos ao longo do curso. Trata-se da prática da sistematização, que poderá ser levada a efeito através de atividades orais e escritas sempre que se fizer necessárias. Obviamente, deve-se evitar que tais atividades sejam desprovidas de sentido; ou seja, devese agregar alguma significado a elas, a fim de que não se tornem meros exercícios gramaticais.

Mas há uma limitação verificada por experiência própria e também apontada por Richards (1990, p.79) em relação ao ensino da conversação por meio de tarefas comunicativas. Referimo-nos ao tipo de interação que se costuma praticar durante as tarefas comunicativas. Com efeito, concordando com o citado autor, as interações levadas a efeito nos pair-works focalizam a troca de informações, a negociação de sentidos, etc., mas "ignoram o uso da conversação para crial interação social e relações sociais". Os usos interacionais da conversação "são muito diferentes tanto na forma como na função dos tipos de transação lingüística realizados durante as tarefas, e devem ocupar uma posição central num curso de conversação". Nessa 
perspectiva, faz-se necessário um esforço para incorporar, de forma explícita e direta, num programa voltado para a conversação, o ensino de estratégias para a interação conversacional.

\section{O ensino de estratégias conversacionais - uma abordagem direta}

O ponto de partida para o planejamento de um curso ou programa que envolva práticas conversacionais é, naturalmente, o entendimento da natureza da conversação natural enquanto evento comunicativo e a dinâmica da interação conversacional. A análise das necessidades comunicativas dentro do provável contexto de uso real da LE pelos aprendizes fornecerá os temas a ser abordados e em torno dos quais as interações conversacionais deverão ocorrer. Nesse sentido, como também sugere Richards (1990, p.79), é necessário que se contemplem alguns aspectos da conversação, tais como estratégias para tomada de turno, controle temático da conversa, reparações; além das rotinas conversacionais, fórmulas sociais e outros elementos como fluência, pronúncia, entonação, registros e estilos conversacionais. Convém salientar que dentre as funções comunicativas selecionadas, muitas delas cumprirão o papel de estratégias conversacionais relevantes e também agirão como recursos modalizadores, atenuadores, enfatizadores, etc. na enunciação. ${ }^{7}$

Para iniciar a elaboração de um programa com ênfase na conversação, nessa abordagem direta, deve-se ter em mente certas metas, dentre as quais, podem ser citadas as seguintes: ${ }^{8}$

7 Vejamos as seguintes interações e suas elocuções:

1) A- "Do you have some time to spare? I'd like to talk to you. There's something I have to tell you but I don't where to begin... I think you know Rosaly, don't you? She's..."

B - "What about her? Please, go straight to the point. I'm curious." Aqui o falante A usa um dos expoentes lingüísticos para a função "como preparar o terreno para se dizer algo desagradável a alguém" e, ao mesmo tempo, tem-se uma estratégia para se iniciar uma conversa. Já o falante B toma o turno demonstrando interesse e pedindo objetividade.

2) A- "Is it true that Mariana got married?

B- "Well, it must be true. At least that's what I heard" Neste diálogo o falante B expressa suposição e dúvida através de modalizadores.

8 Para a descrição dessas metas utilizamos subsídios de Richards (1990), Marcuschi (1986) e nossa própria experiência como professora de inglês, por longos anos, do Instituto de Idiomas Yázigi.. 
- uso de funções comunicativas adequadas às interações e situações diversificadas;

- a produção de turnos curtos e longos na conversação:

- o uso de estratégias para o manejo da tomada de turnos na conversação, incluindo a tomada, a manutenção e a entrega dos turnos;

- o uso de estratégias para abrir e fechar conversações;

- o uso variado de registros e maneiras de falar, ou seja, o estilo mais espontâneo (casual), o neutro e o formal;

- o uso de rotinas conversacionais (expressões formulaicas):

- o uso de conversações em diferentes cenários, situações e encontros sociais, tais como reuniões informais $e$ cerimoniosas, conversas ao telefone, fofocas, etc.

- o uso de estratégias para reparações de situações embaraçosas, quebras na comunicação e problemas de compreensão;

- o uso de marcadores conversacionais, tais como sinais conversacionais por parte do falante e do ouvinte (de concordância, de discordância, de encorajamento), etc.

Cada uma dessas metas, no desenvolvimento do curso ou programa, deve ser descrita mais detalhadamente em forma de objetivos, de acordo com o nível de proficiência com que se está trabalhando (básico/intermediário/avançado), com os tópicos abordados nas unidades de ensino, os cenários da interação, os papéis sociais assumidos pelos interactantes, e outros fatores do entorno conversacional.

Um aspecto importante a ser considerado é a questão do material didático e as atividades de sala de aula. Obviamente, os recursos de ensino e aprendizagem devem contemplar não só os procedimentos que envolvem professor e alunos na sala de aula mas também os exercícios complementares de sistematização linguiística. além de também estimular a gradativa autonomia dos alunos na busca de fontes alternativas de estudo. Especificamente, ainda no que respeita às atividades, Littlewood (1990, p.86) distingue-as em précomunicativas (atividades com considerável ênfase estrutural e outras semi-comunicativas) e comunicativas (atividades em que predominam os aspectos comunicativo-funcionais e sócio-interacionais). 
As técnicas para manejo das práticas conversacionais na sala de aula devem privilegiar o role-playing, que deve ser precedido de atividades monitoradas para se dar ênfase ao aspecto da conversação que se quer praticar. Essas atividades preparatórias para o trabalho interacional em pares ou pequenos grupos podem incluir brainstorming, tarefas do tipo problem-solving, active listening, e outras que se fizer adequadas, em que se proverá o vocabulário necessário e se praticarão as funções comunicativas que podem ser usadas na interação. Depois, o role-playing é realizado seguindo-se um esquema que contenha os elementos básicos da interação: o tópico, a situação, os papéis dos interactantes e o propósito comunicativo.

Convém salientar que boa parte dos livros didáticos de base comunicativa e funcional já há algum tempo trazem propostas de ensino da conversação nessa tendência mais diretamente enfatizadora dos aspectos pragmáticos conversacionais. No Brasil, a primeira experiência nessa linha e da qual temos notícia é a série de livros do Programa English in Brazil (para o nível básico); a série Imagine (para o nível intermediário) e a série Quest (para o curso avançado), todos eles desenvolvidos pelo Centro de Lingüística Aplicada do Yázigi durante a década de 80 .

Para quem trabalha com treinamento de professores de LEs nessa linha sociointeracional, funcional e pragmática, a dificuldade maior é exatamente desenvolver no professor o incremento da chamada consciência pragmática, para que ele possa sensibilizar os alunos para a percepção dos componentes retórico-discursivos envolvidos nas interações sociais intermediadas pela linguagem. Segundo Busnardo Neto \& El-Dash (2000, p.45), a consciência pragmática "começa, antes de mais nada, com o reconhecimento de que existe um nível, além do léxico-gramatical, que interessa ao aluno de línguas. Fala-se muito em ir 'além da gramática', mas poucos alunos têm noções claras sobre o que seria esse 'além'”. Sem dúvida, a competência comunicativa precisa dessa consciência pragmática. E o ensino de LEs pode contribuir para isso, com reflexos positivos também para a língua materna. Como o ensino das LEs sempre esteve na vanguarda da linguística aplicada, um grande passo já foi dado com a utilização de conteúdos compostos por funções comunicativas, levando os aprendizes a trabalharem de forma significativa com esses atos de fala. Espera-se que todo o investimento feito nesse sentido venha a se incorporar nas habilidades produtivas dos aprendizes, 
configurando, assim, um processo de transformação de aprendizagem em aquisição de língua. A prática conversacional é, portanto, uma maneira eficaz de contribuição efetiva para esse processo.

A tentativa de ensino da conversação sempre ocorreu nas abordagens e métodos de ensino de LEs engendrados pelas teorias da lingüística moderna. Entretanto, a maneira como era concebida a língua e a sua aquisição e aprendizagem na abordagem estrutural (privilegiadora da forma idealizada e não do uso efetivo da língua) levou a uma prática estéril de expressão oral nas LEs que em nadi correspondia à verdadeira natureza da conversação. Os métodos de ensino de base estrutural na realidade distorceram consideravelmente o que costuma chamar de conversação.

Foi só a partir da lingüística do discurso, das teorias sociolingüísticas, da visão sociointeracional da língua, da pragmática lingüística e da etnografia da comunicação que a conversação passou a ser vista como objeto de estudo e também como uma atividade prioritariamente propícia à aquisição das línguas naturais e, por extensão, à aquisição e aprendizagem de LEs.

Vimos que duas abordagens, dentro do movimento comunicativo de ensino de LEs, têm dado tratamentos diferenciados ao ensino da conversação. Um deles - aqui referido como abordagem indireta - prioriza os aspectos interacionais do uso da língua através de tarefas comunicativas. O outro tratamento prioriza o aspecto funcional e pragmático da língua e da conversação através do ensino explícito de atos de fala e de recursos estratégicos que comumente são postos em uso na atividade conversacional.

Acreditamos, em consonância com Richards (1990:84), que as duas tendências não se excluem; pelo contrário, elas são complementares. Assim sendo, um programa de ensino de LEs razoavelmente eficaz deve contemplar as duas abordagens, incorporando, desse modo, as tarefas comunicativas e os procedimentos relativos ao uso dos componentes funcionais, pragmáticos e estratégicos da conversação. Um ponto crítico a ser observado nesse ensino deve ser o equilíbrio entre os aspectos interativos, funcionais e pragmáticos da língua e os cuidados com a necessária sistematização dos seus aspectos formais. Desse modo, estarse-á, possivelmente, contemplando tanto os processos de aquisição quanto os de aprendizagem da LE. 


\section{Referências bibliográficas}

AlmeIda FILHO, José Carlos P. de. Dimensões comunicativas no ensino de línguas. Campinas: Pontes, 1983.

ALMEIDA FILHO, José Carlos P. de. Fundamentação e crítica da abordagem comunicativa de ensino de línguas. Trabalhos em Lingïística Aplicada. Campinas, IEL/Unicamp, n. 8, p.85-91,1986.

ALMEIDA FILHO, José Carlos P. de. Ambientes comunicativos para aprender língua estrangeira. Trabalhos em Lingiuística Aplicada, n.36, p. 23-42, jul./dez. 2000.

AUSTIN, John L. How to do thing with words. Harvard: Clarendon Press, 1962. Edição em língua portuguesa com o título Quando dizer é fazer - Palavras e ação. Tradução Danilo Marcondes de Souza Filho. Porto Alegre: Artes Médicas, 1990.

BUSNARDO NETO, Joanne M. \& EL-DASh, Linda Gentry. Iniciação na Pragmática: Reflexões sobre a conscientização pragmáticas para professores e alunos de línguas. Trabalhos em Lingiuística Aplicada, n. 36, p. 43-50, jul./dez. 2000.

COSGRAVE, Desmond P. From pattern practice to communication. Forum - Special Issue: The Art of TESOL, Part 1, p.141-149, 1975.

DIONÍSIO, Ângela Paiva. Análise da Conversação. MUSSALIN, Fernanda e BENTES, Anna Christina. Introdução à lingiḯstica domínios e fronteiras. Vol. 2. São Paulo, Cortez Editora, 2001,p. 69-99.

GARNER, John E. \& SHULTZ, Noel W. The missing link in our English instruction. Forum - Special lssue: The Art of TESOL, 1975. Part 1, p. 126-130.

HATCH, E. Second Language Acquisition. Rowley, Massachussets. Newbury House, 1978.

HYMES, Dell. On communicative competence. In: Pride, J. B. \& Homes, J. (Eds.). Sociolinguistics. Penguin Books, 1971

LEVINSON, Stephen. Pragmatics. Cambridge, Cambridge University Press, 1983.

LITLEWOOD, William. Communicative language teaching - An introduction. Cambridge University Press, 1990.

MARCUSCHI, Luiz Antônio. Análise da conversação. São Paulo, Ática, 1986 (Princípios, 82). 
NUNAN, David. Designing tasks for the communicative classroom. New York, Cambridge University Press, 1989.

RILEY, Philip (Ed.). Discourse and learning - Papers in applied linguistics and language learning from the Centre de Recherches et d'Applications Pédagogiques en Langues (C.R.A.P.E.L.). LondonNew York, Longman, 1985.

RICHARDS, Jack C. The language teaching matrix. Cambridge, Cambridge University Press, 1990. Conversationally speaking: approaches to the teaching of conversation, p.67-86.

SEARLE, John. Speech Acts - An essay in the philosophy of language. London, Cambridge University Press, 1969. Edição em língua portuguesa com o título Os Actos de Fala - um ensaio de filosofia da linguagem. Coimbra: Livraria Almedina, 1981.

SILVEIRA, $\mathrm{M}^{\mathrm{a}}$ Inez Matoso. Línguas estrangeiras - uma visão histórica das abordagens, métodos e técnicas de ensino. Maceió: Editora Catavento, 1999.

SOUZA, Lynn Mário Trindade M. de. O que é saber uma língua estrangeira. São Paulo: Centro de Lingüística Aplicada do Instituto de Idiomas Yázigi, 1983 (mimeo). 